Military Technical College Kobry El-Kobbah, Cairo, Egypt

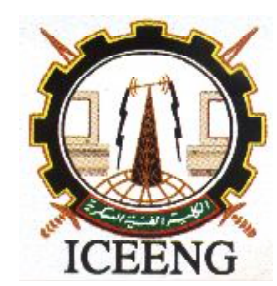

$10^{\text {th }}$ International Conference on Electrical Engineering ICEENG 2016

\title{
Controlling the Combustion Process of Thermal Power Plants to Reduce the Amount of Carbon Dioxide Produced
}

\author{
By \\ Roshdy AbolAzayem AbdelRassoul*, S.M. IEEE, Mohamed Saad Zaghloul*, Mohamed M. M. Omar \\ and Islam Youssry El Adly*
}

\section{Abstract:}

In this paper we discuss the increasing of power plant efficiency by enhancement the operation of the combustion chamber and controlling the amount of injected air to combustion chamber and the amount of fuel used to minimize the heat rate of the power plant and decrease the fuel consumption to reduce the amount of the exhaust produced from the operation, the gas optical sensor used to detect the amount of exhaust gases , the design, how it work and way of using output data from the sensor to control the operation and reduce the amount of exhaust produced for less heat rate and fuel consumption and more power plant efficiency.

\section{Keywords:}

Combustion chamber, optical gas sensing, fuzzy mining, compressed air

* Arab Academy for Science, Technology and Maritime Transport, Alexandria, Egypt. 


\section{Introduction:}

Every moment need for more energy production increases and fossil production rate increases to supply the continuous need of it to produce more power and several usage, due to this increasing rates of power need so it becomes a great problem for every country, so producing more power needs new ways to provide power with lower fuel consumption and minimum amount of exhausts, due to the increasing of power production using fossil fuel in many factories that causes increasing the amount of co in the air which effects the humane health [1,2].

Many ways were discussed in this paper to increase the efficiency of the power plants and reducing the amount of the produced exhausts caused from combustion process, to provide more power with the same quantity of fossil fuel and increasing the heat rate of the power plant to produce needed energy, the increment in fuel consumption causes the growing of needed fossil fuel that decrease the available amount of fossil fuel and rises the price of it causing maximization of energy production cost [2,3].

The power plant with efficiency up to $100 \%$ the chemical energy in the fuel converted into electricity, the thermal plant would have a heat rate of $860 \mathrm{kcal} / \mathrm{kWh}$. Due to the losses a modern conventional power at best a design with full load heat rate of the order of $2200 \mathrm{kcal} / \mathrm{kWh}$, which is about $39 \%$ efficient. So we need to reduce losses that cause the decreasing of power plant efficiency [4].

the paper is divided into several parts that explains the combustion chamber its design and how it works were explained in part (1), the problem formulation that causes the reduction of combustion process efficiency were illustrated in part (2), the proposed solution explained in part (3), the conclusion and the change in efficiency due to applying the usage of solution briefly mentioned in part (4).

\section{2. combustion chamber design:}

The combustion chamber is the main component of the gas turbine in which the fuel is combined with the air from the compressor and burned. The combustor burns a fuel-air mixture and delivers the products of combustion to the turbine at temperatures within design range as shown fig.1. 


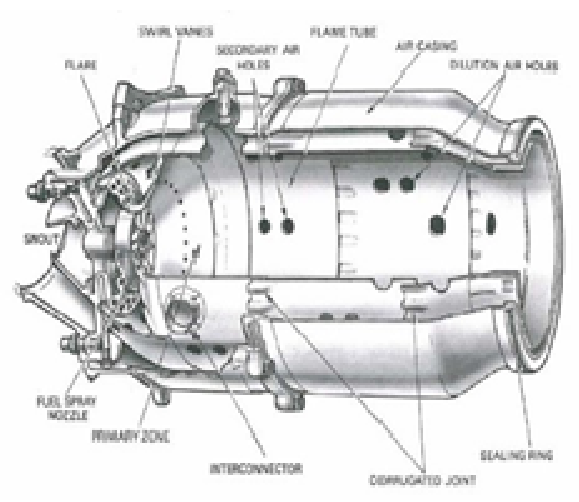

Figure (1): A combustion chamber

There are three main combustion chamber types in use today:

- Annular combustor chambers

- can (multi-can) combustor chambers

- Can-annular combustor chambers

The annular combustion chamber can enhance a geometrically compact design. Instead of individual combustion chamber cans, compressed air is introduced into an annular space formed by a chamber liner around the turbine assembly. An annular combustion chamber provides a larger combustion volume per unit of exposed metal area and therefore of metal weight [8].

The can combustion chamber design has individual combustion chambers. Air from the compressor enters each individual chamber through a transition section. Each individual can has two cylindrical tubes, concentric in most locations, the combustion chamber liner and the outer combustion chamber Combustion occurs within the inner liner [8].

The Can-annular combustion chamber this combustion chamber is a combination of both annular and can-type designs. The can-annular combustion chamber consists of an outer shell (annular), with a number of cans mounted about the engine axis [8].

The combustion chamber can be divided into two areas: the primary zone and the secondary zone. The primary zone is where the majority of the fuel combustion takes place. In the secondary zone, unburned air is mixed with the Combustion products to cool the mixture before it enters the turbine cooling air drops this temperature to a value that the turbine inlet guide vanes can withstand. The air used for burning fuel is "primary" air. Cooling air is "secondary" air and is controlled and directed by holes and louvers in the combustion chamber liner [8].

Fuel is injected at the upstream end of the burner in a highly atomized spray. Fuel nozzles may be simplex type (delivering gaseous fuel or liquid fuel) or they may be designed to be dual fuel (delivering gas or liquid at different times in the operation). Some gas turbines are "bi- fuel". They may burn a mixture of gas and liquid fuel [8]. Combustion air, with the help of swirled vanes, flows in around the fuel nozzle and mixes with the fuel. This air is called primary air and represents approximately 25 
percent of total air ingested by the engine. The fuel-air mixture by weight is roughly 15 parts of air to 1 part of fuel. The remaining 75 percent of the air is used to form an air blanket around the burning gases and to lower the temperature [8].

However when the fuel is burned inside the chamber the chemical reaction that takes place changes the state of the air and the fuel. The combustion process raises the temperature of the air in the system by converting the chemical potential energy of the reactants to thermal energy [12]. There is no work transfer involved in the reaction. Therefore, the first law of thermodynamics for steady flow operation of the combustion chamber becomes [9]

$\mathrm{Q}=\Sigma(\mathrm{mh})_{\text {out }}-\sum(\mathrm{mh})_{\text {in }}$

However when the fuel is burned inside the chamber the chemical reaction that takes place changes the state of the air and the fuel. The first law for the combustion reaction becomes [15]

$\mathrm{Q}=\sum(\mathrm{h})-\sum(\mathrm{h})$

Where is the flow rate of the individual reactants and products in mols per second .The enthalpies of each product and reactant are determined by the sum of the

enthalpy of formation at standard temperature and pressure $h_{t^{\circ} p}$ and the enthalpy

required to raise the compound from the standard temperature of $25^{\circ} \mathrm{C}$ to the desired temperature [9].

$\bar{h}_{t, p}-\bar{h}_{25^{0}, \text { latm }}=0.125 \mathrm{~kg} / \mathrm{sec}$

$\mathrm{c}_{3} \mathrm{~h}_{8}+5 \mathrm{o}_{2}+5(3.67) \mathrm{n}_{2} \rightarrow 3 \mathrm{co}_{2}+4 \mathrm{~h}_{2} \mathrm{O}+5(3.76) \mathrm{n}_{2}$

For a gas turbine running on propane, Propane is mixed with stoichiometric air and burned to form carbon-dioxide and water. The amount of air and propane that needs to be burned in the combustion chamber was calculated by analyzing the combustion reaction. The air flow through the compressor needed to be estimated. From the BorgWarner performance diagram for the compressor the operating point of the compressor was taken to be at a corrected mass flow rate of $0.125 \mathrm{~kg} / \mathrm{sec}$ with a pressure ratio of 2 and an efficiency $\mu \mathrm{c}=0.72$ Atmospheric air enters the compressor at a temperature, $\mathrm{T} 1=298 \mathrm{~K}$, and a pressure $\mathrm{P} 1=105 \mathrm{~N} / \mathrm{m} 2$. Combining these values with Equation

$\dot{m} \sqrt{\frac{t_{1}}{t_{0}}} \frac{p_{0}}{p_{1}}=0.125 \mathrm{~kg} / \mathrm{sec}$

Gives a mass flow rate of air in the compressor, $\mathrm{m}_{\text {air }}$ of $0.918 \mathrm{~mol} \mathrm{Air} / \mathrm{sec}$. 


$$
\dot{\mathrm{m}}_{\text {air }}=\frac{(0.126 \mathrm{~kg} / \mathrm{sec})}{(\mathrm{mol} \text { air }) / 0.1373 \mathrm{~kg})}=0.918(\mathrm{~mol} \mathrm{air} / \mathrm{sec})
$$

The actual outlet temperature of the compressor, T2 was estimated to be $388.64 \mathrm{~K}$.

$$
\mu_{c}=\frac{\left(\mathrm{T}_{2 \mathrm{R}}-\mathrm{T}_{1}\right)}{\left(\mathrm{T}_{2}-\mathrm{T}_{1}\right)} \rightarrow t_{2}=388.64 k
$$

It is the temperature of the air at the outlet of the compressor and the temperature of the air on the reactant side of the combustion reaction, so to determine the flow rate of air through the turbine and the flow rate of propane required to reach the turbine inlet temperature can be calculated from the combustion reaction

$\mathrm{C}_{3} \mathrm{H}_{8}+5 \mathrm{O}_{2}+5(3.67) \mathrm{N}_{2} \rightarrow 3 \mathrm{co}_{2}+4 \mathrm{H}_{2} \mathrm{O}+5(3.76) \mathrm{N}_{2}$

Assumes that there is a stoichiometric ratio of air to propane. However, for design purposes some of the air from the compressor is used to cool the products of combustion. Therefore all of the propane burns, but some of the air does not. Letting $x$ represent the molar flow rate of propane and y letting represent the molar flow rate of air and assuming that there is no heat transfer out of the combustion chamber, so the combustion reaction becomes [9]

$\dot{\mathrm{x}} \mathrm{h}_{\left(\mathrm{C}_{3} \mathrm{~h}_{8}\right)}+\dot{\mathrm{y}} \mathrm{h}_{\left(\mathrm{o}_{2}\right)}+(3.67) \dot{\mathrm{y}} \mathrm{h}_{\left(\mathrm{n}_{2}\right)} \rightarrow 3 \dot{\mathrm{x}} \mathrm{h}_{\left(\mathrm{co}_{2}\right)}+4 \dot{\mathrm{x}} \mathrm{h}_{\left(\mathrm{h}_{2} \mathrm{o}\right)}+(\dot{\mathrm{y}}-5 \dot{\mathrm{x}}) \mathrm{h}_{(02)}+3.67 \dot{\mathrm{y}} \mathrm{h}_{(\mathrm{n} 2)}$

So by solving the equation the mass flow rate of propane, $\mathrm{m}_{\mathrm{C} 3 \mathrm{H} 8}$, of $0.001232 \mathrm{~kg} / \mathrm{sec}$, to stoichiometrically balance the air with the propane, the mass of burned air per second must be $0.019 \mathrm{~kg} / \mathrm{sec}$, Therefore the percentage of air flow from the compressor that must be burned is

$\frac{\dot{\mathrm{m}}_{\text {burned air }}}{\dot{\mathrm{m}}_{\text {air }}}=0.153$

This means that $15.3 \%$ of that air flow should be directed through the flame tube section of the combustion chamber [9].

\section{Problem formulation}

The objective of good combustion is to release all of the heat in the fuel. This is accomplished by controlling the "three T's" of combustion which are (1) Temperature high enough to ignite and maintain ignition of the fuel, (2) Turbulence or intimate mixing of the fuel and oxygen, and (3) time sufficient for complete too much, or too little fuel with the available combustion air may potentially result in unburned fuel and carbon monoxide generation. A very specific amount of $\mathrm{O} 2$ is needed for Perfect combustion and some additional Excess air is required for ensuring complete combustion. However, too much excess air will result in heat and efficiency losses. If it were possible to have perfect combustion, $\mathrm{CO} 2$ would be maximized and $\mathrm{O} 2$ would be at, or close to, zero in the flue gas stream. Because perfect combustion is not practically 
possible, most combustion equipment is set up to have a small percentage of excess $\mathrm{O} 2$ present. The lower the temperature for a given $\mathrm{O} 2$ or $\mathrm{CO} 2$ reading, the higher is your combustion efficiency. This is because less heat is lost up the stack. In a Stoichiometric Mix, all the fuel and oxygen $(\mathrm{O} 2)$ present combines to generate only heat, water and carbon dioxide (CO2). Smoke is the usual indicator of uncompleted combustion in oil burners. In addition to indicating poor combustion, smoke can deposit soot on your heat exchangers which will further reduce fuel efficiency, and cause air quality violation.

The stoichiometric ratio is the perfect ideal fuel Ratio where the chemical mixing proportion is correct. When all fuel and air burned is consumed without any excess left over. Combustion used in boilers and high temperature process furnace usually Incorporates a modest amount of excess air needed to burn the fuel completely.

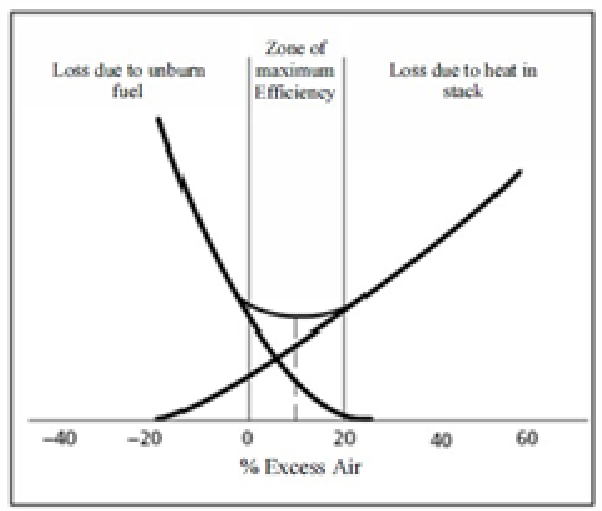

Figure (2):Boiler efficiency based on the amount of excess air [12]

Small amount of excess air will improve combustion efficiency, but a large amount will reduce efficiency and if incomplete combustion occurs, the chemical energy of the fuel is not completely released as heat and the combustion efficiency is reduced, as shown in the Fig.2 [12].

If sufficient oxygen ions are not available either due to insufficient air or due to nonhomogenous mixture carbon dioxide is produced as an intermediate compound: ${\mathrm{C}+\mathrm{O}_{2}} \rightarrow 2 \mathrm{co}$

Most of the $79 \%$ of air is nitrogen for uncompleted combustion process that Nitrogen reduces combustion efficiency by absorbing heat from the combustion of fuels and diluting the flue gases. This reduces the heat available for transfer through the heat exchange surfaces. It also increases the volume of combustion by- products, which then have to travel through the heat exchanger and up the stack faster to allow the introduction of additional fuel air mixture. That nitrogen also can combine with oxygen (particularly at high flame temperatures) to produce oxides of nitrogen $\left(\mathrm{NO}_{\mathrm{x}}\right)$, which are toxic pollutants.

\section{Proposed solution:}


The proposed solution is to detect any small change in the element of the produced gases from the combustion process and specially the increasing of the amount of carbon monoxide that produced with more quantity when the amount of used air in combustion process is not enough to produce near ideal combustion process to identify if there are need to increase the amount of the injected air.

Using optical sensor used to detect the change in carbon dioxide concentration with very high Accuracy. Range. This sensor is a $700 \mathrm{~nm}$ square lattice macro porous structure was fabricated by electrochemical etching, creating a photonic gap centered at the 4.2 $\mathrm{m}, \mathrm{a} \mathrm{CO}_{2}$ absorption line. The obtained results rely only on the absorption spectra measurement depend on the change in spectrum due to carbon dioxide absorption. [14]

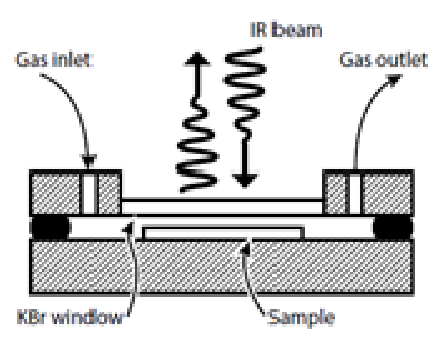

Figure (3): Gas cell. The sample is placed in an airtight volume. IR light reaches the sample through a potassium bromide $(\mathrm{KBr})$ window. The separation from the sample to the window is $0.5 \mathrm{~mm}$ [14].

Afterwards the sample was placed in an enclosed cell (schematically shown in Fig.3 [14]) through which $\mathrm{CO}_{2}$ flows at different concentrations. Reflectance was measured at normal incidence through a potassium bromide window separated by $0.5 \mathrm{~mm}$ from the sample. Measurements were taken with a $50 \mathrm{~m} \times 50 \mathrm{~m}$ aperture and a 128 averaging factor [14]. It was found, as can be seen in Fig. 4, that the structure has a certain amount of geometry variation pore-to pore and in-pore [14]. This is especially evident in the wall thickness between pores. This variability is due to the complex control of the electrochemical fabrication step corresponding to a resonance of carbon dioxide $\left(\mathrm{CO}_{2}\right)$.




Figure (4): SEM image of the sample. This sample has increased porosity. Soft modulation and periodicity variability can be observed [14].

Using a broadband light source, such as an LED or a thermal radiator, shone to the PC, it is possible to filter out the unwanted spectrum and keep only the region corresponding to the gas absorption band. Looking the change in the peak amplitude after passing through a layer of gas, it is possible to determine its concentration. This sensor works by detecting the change in reflectance, as an indirect measure of absorbance.

The samples were initially evaluated by extracting their reflectance spectral response at quasi-normal incidence using a FT-IR system.

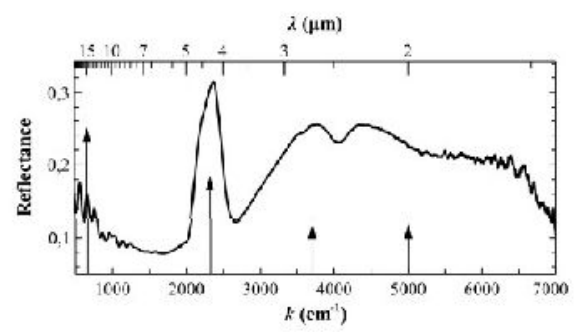

Figure (5): Reflection spectra of the fabricated sample. CO2 absorption lines are marked as arrows [13].

Using pc simulation shown in fig. 5. With only a $30 \%$ reflectance [14]. This correlates with the earlier SEM analysis. Though structure irregularities create light scattering and weakened resonances, nevertheless, the obtained band gap is clear enough to allow the detection of the presence of carbon dioxide.

That fault in combustion process could cause efficiency reduction of combustion process causing lower efficiency of the power plant and increasing of the output exhausts as carbon monoxide (CO) and oxides of nitrogen (NOx). By using numerous sensors that sensors detect that increasing and send data to fuzzy data mining (Fuzzy Association Rule not explained in this paper)[13]. The fuzzy data mining technique are Applied to preprocess data and good results on these data are obtained, the method is applied here is the Fuzzy association rules. For each class, the optimal excess air which is commensurate with amount of carbon dioxide and other parameters is calculated to identify the amount if excess air required to complete the combustion process, as shown in fig. 6 [12]. 


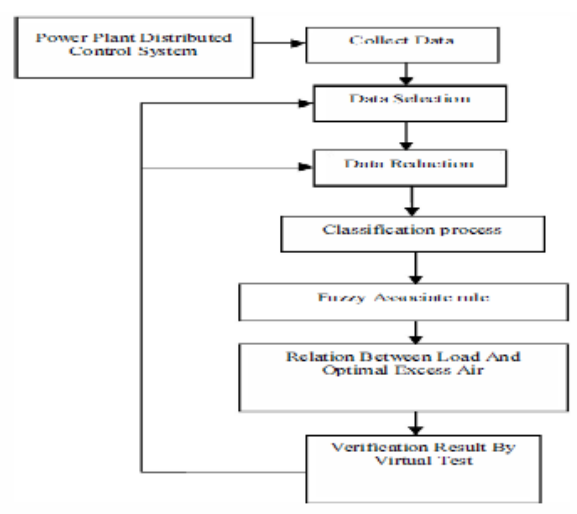

Figure (6): Flowchart fuzzy data mining [12].

A. Data Collection system

The D C S distributed systems collect the combustion process run-time data by optical sensor.

B. Data selection

The data sampling time is set to one second in this step, after recognition of effective Parameters on problem, the required data are selected. The data sampling time is set to one second and Data parameters of the boiler including output steam flow (ton/h), the amount of excess air (\%), boiler efficiency (\%) and Boiler Flue temperature ( 0 C) are stored in a Single week, a sample of these data. At the same time, the boiler's efficiency is computed by the predefined equations and experimental data.

E. Fuzzy data mining

The fuzzy data mining technique are Applied to preprocess data and good results on these data are obtained, the method is applied here is the Fuzzy association rules. For each class, the optimal excess air which is commensurate with the amount of carbon dioxide and other parameters is calculated.

F. Obtaining relation

Relation between load and excess air use of regression to fit a curve to the data obtained in previous step and to obtain a final equation in terms of amount of carbon dioxide and optimal excess air.

G. Virtual test:

Modeling of boiler system and evaluating the performance of the calculated optimal excess air on boiler efficiency.

After compiling the collected data and measuring the increase of the carbon monoxide amount and calculating the amount of excess air required to complete the combustion process, the accepted ranges which is about $80 \%-85 \%$ of the input amount of gas fuel for natural gas so using gas turbine compressed air system (GT-CAS) [13].

(GT-CAS) consist of two parts small scale chamber and large scale chamber, small scale chamber that what will be used when the need for excess air this chamber store compressed air with pressure is slightly higher than the pressure in the combustion 
chamber, so that air mass flow is spontaneous when the valve opens.

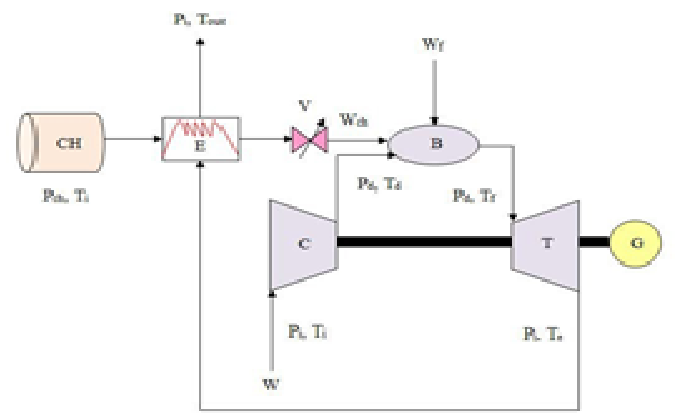

Figure (8): Gas-Turbine unit with air injection in combustion chamber.

The compressed air is preheated to the same temperature as the air coming from the compressor this is achieved through the heat exchanger, which transfers part of the thermal energy of the exhaust gases from the turbine to the compressed air flow. That the two air currents have the same thermodynamically properties.

\section{Conclusions:}

This paper illustrates the different designs of combustion chamber; the main differences between these designs in the combustion process, the combustion process were explained taking into consideration effect of injected air amount, which affect the value of carbon dioxide and oxide of nitrogen. These two gases affect the pollution and the power plant efficiency. Detecting of these two gases (CO.NO) using optical sensors, the result of this detection is used to control the flow of injected air such to minimize the output of these two gases. Applying the previous closed loop control we able to increase the efficiency of the combustion process from $70 \%$ to $85 \%$.

\section{References:}

[1] Everett b. woodruff, Herbert b. lammers, and Tomas f. Lammers, Steam plant operation, ch2 - ch5, eighth edition, 2000, McGraw-Hill, 2005.

[2] K. Krishnaswanami, Bala M. Ponni 'Power plant instrumentation' ch4, Second Edition, Prentice-Hall of India Pvt.Ltd (June 2011).

[3] A. K. Shaha, Combustion Engineering and Fuel Technology, Oxford \& IBH Publishing Company, Edited by WorkBot, December 15, 2009.

[4] Balaram saha1, Vivek patel2, Kalyan chaterjee3, Assessment of Process Parameter to Improving power Plant Performance, International Conference on Innovative Applications of Computational Intelligence on Power, Energy and Controls with their Impact on Humanity (CIPECH14) 28 \& 29 November 2014.

[5] James L. Bergmann, COMBUSSTTIION ANALYSIS, Testo Combustion Applications Guide, testo, Inc. Rev. 1.0, 2006.

[6] Larry Caretto, Introduction to Combustion Analysis, Number: 17724, spring 2010 
[7] P. Sravan Kumar, P.Punna Rao, Design and Analysis of Gas Turbine Combustion Chamber, International Journal of Computational Engineering Research (ijceronline.com) Vol. 03 Issue. 12, December 2013.

[8] Claire M. Soares, Gas Turbines In Simple Cycle \& Combined Cycle Applications,

[9] Lauren Tsai, Design and Performance of a Gas-Turbine Engine from an Automobile Turbocharger, 2004.

[10] Antal Penninger, Ference Lezsosivts, Janos Rohaly, Vilmos Wolff, Combustions (heat engines and boilers) lecture notes and undergraduate BSc course, available from ftp://152.66.39.22/pub/Heat_Engines/Lecture_Notes April 2011.

[11] Grzegorz Wielgosiński ,Pollutant Formation in Combustion Processes, Technical University of Lodz, Faculty of Process and Environmental Engineering, Poland, 2012.

[12] TSI Incorporated, Combustion Analysis Basics an Overview of Measurements, Methods and Calculations Used in Combustion Analysis, Copyright ( 2004.

[13] Mehdi Parsa, Ali Vahidian Kamyad and Mohammad Bagher Naghibi Sistani, Combustion Efficiency Optimization By Adjusting The Amount Of Excess Air, The 5th Conference on Thermal Power Plants (IPGC2014), Shahid Beheshti University, Tehran, Iran, June 10-11, 2014.

[14] I. Kandiloros, C. Vournas, Use of Air Chamber in Gas-Turbine Units for Frequency Control and Energy Storage in a System with High Wind Penetration, 5th IEEE PES Innovative Smart Grid Technologies Europe (ISGT Europe), Istanbul, October 12-15, 2014.

[15] Didac Vega, Ángel Rodríguez, Raül Calavia, Xavier Vilanova, Compact Device for CO2 Optical Sensing using Macroporous Silicon Photonic Crystals, 2015 10th Spanish Conference on Electron Devices (CDE) 978-1- 4799-8108-3/151\$31.00, (C) IEEE, 2015.

[16] Michael Biarnes, Bill Freed and Jason Esteves, COMBUSTION, E Instruments International LLC, http://www.E-Inst.com, 2016.

\section{Nomenclatures:}

$\bar{h}$... Enthalpy

$\bar{h} \ldots$ Enthalpy of a particular compound at a given $\mathrm{T}$ and $\mathrm{P}$

$\bar{h}_{t, p} \ldots$ Enthalpy of formation

$\bar{h}_{t, p}-\bar{h}_{25^{0} c, 1 a t m} \ldots$ Enthalpy to raise a compound to temperature T

$h .$. Total hydrostatic end force of combustor flange

$\bar{h}_{p} \ldots$ Total joint contact surface compression load on combustor flange

$\mathrm{m}$... mass flow rate 
$\mu_{c} \ldots$ Efficiency

... molar flow rate

Q ...heat transfer

$\dot{x}$...Molar flow rate of propane

$\dot{y}$...Molar flow rate of air 